\title{
Ultrastructure and Chaetotaxy of Sensory Receptors in the Cercaria of a Species of Allopodocotyle Pritchard, 1966 (Digenea: Opecoelidae)
}

\author{
T Bogéa ${ }^{+}$, JN Caira \\ Department of Ecology and Evolutionary Biology, University of Connecticut, Storrs, \\ Connecticut 06269-3043, USA
}

\begin{abstract}
Previous investigations of sensory systems in opecoelid cercariae have focused on chaetotaxy and ultrastructure of sensory receptors. They revealed chaetotaxic patterns within family, genus, and species as well as different receptors. Chaetotaxic and ultrastructural observations have rarely been combined. We investigated the ultrastructure of cercarial sensory receptors in conjunction with chaetotaxy and neuromorphology in a species of Allopodocotyle. Cercariae were treated with acetylthiocholine iodide and silver nitrate, and some were processed for light, scanning (SEM), and transmission (TEM) electron microscopy. Five nerve regions were distinguished. Chaetotaxy was consistent with that of other opecoelids. Five types of receptors were distinguished with SEM. Types differed in number of cilium-like structures (one or more), length of cilium-like structure (short, moderately long, or long), presence or absence of a tegumentary collar, and length of tegumentary collar (low, moderately low, or very high). Internal ultrastructure of some types revealed unsheathed cilium-like structures, basal body, and thickened nerve collars. Possible subtegumentary and sheathed receptors are introduced. Some receptor types were sitespecific. For example, receptors with multiple cilium-like structures were concentrated on cephalic region whereas receptors with short cilium-like structure were widespread throughout most regions. Ultrastructure and site-specificity observations suggest that most receptors are mechanoreceptors.
\end{abstract}

Key words: cercaria - sensory receptors - Allopodocotyle - chaetotaxy - ultrastructure - functional morphology

The ultrastructure of cercarial sensory receptors has been investigated previously in several species of the family Opecoelidae. Using electron microscopy, Gibson (1974), Lo et al. (1975), and Køie (1981) recognized several types of receptors on the tegument of cercariae of Podocotyle staffordi Miller, 1941, Allopodocotyle lepomis (Dobrovolny, 1939), and Podocotyle reflexa (Creplin, 1825) Odhner, 1905, respectively. These types differed in the presence or absence of a tegumentary sheath, a tegumentary collar, and a discoid base, as well as in number of cilia, cilium length, and length of tegumentary collar.

Several authors have studied the chaetotaxy of opecoelids (Richard 1971, Lambert 1972,

\footnotetext{
${ }^{+}$Corresponding author. Supported by doctoral scholarships of Conselho Nacional de Desenvolvimento Científico e Tecnológico (no. 200142/94-1) and the University of Connecticut. Present address: Departamento de Medicina Tropical, Instituto Oswaldo Cruz, Av. Brasil 4365, 21045-900 Rio de Janeiro, RJ, Brasil. Fax: +55-21-280.3740. E-mail: tbogea@ioc.fiocruz.br Received 5 April 2000 Accepted 27 October 2000
}

Bayssade-Dufour \& Maillard 1974). Based on their observations, Bayssade-Dufour (1979) established the arrangement of cephalic circle $\mathrm{CI}$ as diagnostic for the family Opecoelidae.

In the present study, we aimed to extend the use of a combination of techniques to the study of a species in the genus Allopodocotyle Pritchard, 1966. Thus, the ultrastructure of sensory receptors in the cercaria of Allopodocotyle sp. was investigated in conjunction with their distribution on the tegument and their position relative to the nerve network by examination with the acetylthiocholine method for cholinesterase, silver nitrate impregnation, and scanning (SEM) and transmission (TEM) electron microscopy, as suggested by Bogéa (1998, 1999).

\section{MATERIALS AND METHODS}

Specimen collection and identification - Bottom sediment was collected with the aid of dip nets and sieved through 0.25 " mesh aluminum screening. A total of 62 individuals of the snail Juga plicifera (Lea, 1838) (Gastropoda: Pleuroceridae), with shell lengths of approximately $2 \mathrm{~cm}$, was collected in Eagle Creek, Estacada, Oregon, USA, in September 1997 by K Tiekotter. The snails were transported to the laboratory in vials containing pond water and then shipped overnight to the authors. 
In the laboratory, the infected snails were identified and individually isolated in glass vials with $5 \mathrm{ml}$ of pond water. They were then exposed to artificial light (60 watts) and temperature (approximately $30^{\circ} \mathrm{C}$ for up to $1 \mathrm{~h}$ ) every two days for up to two weeks to induce cercarial emergence.

Twenty cercariae were collected with fine glass pipettes and processed as whole mounts. They were fixed in hot $5 \%$ buffered formalin phosphate, hydrated through a graded ethanol series, stained with Semichon's acetocarmine, dehydrated in a graded ethanol series, cleared in methyl salicylate, and mounted in Canada balsam on glass slides. Illustrations of each specimen showed its general morphology with the aid of a drawing tube. Taxonomic identifications followed descriptions in McIntosh (1939), Shaw (1947), Pritchard (1966), Gibson and Bray (1982), and Bray (1987). The present taxon was referred to as 'sp.' because cercariae were not reared out through second intermediate and definitive hosts and thus specific identification was not confirmed. Voucher specimens of the cercaria have been deposited in the Instituto Oswaldo Cruz Helminthological Collection (CHIOC), Rio de Janeiro, Brazil, No. 34290 a-b.

\section{Specimen preparation and study}

Acetylthiocholine method for cholinesterase Twenty cercariae were fixed in cold $4 \%$ paraformaldehyde in phosphate buffer, incubated in acetylthiocholine iodide substrate, rinsed in a solution of sodium sulfate, washed thoroughly in distilled water, and developed with $3 \%$ silver nitrate. They were then treated with Bodian's developer, fixed in a solution of $1.5 \%$ glutaraldehyde $/ 1.5 \%$ formaldehyde in $0.1 \mathrm{M}$ cacodylate buffer, dehydrated in a graded series of ethanol, cleared in methyl salicylate, and mounted in Canada balsam on glass slides (Thompson 1966). Controls consisted of pre-incubation of 20 specimens in $1 \times 10^{-5} \mathrm{M}$ eserine sulphate in phosphate buffer. Illustrations of each specimen recorded the basic arrangement of the nerve network with the aid of a drawing tube. A single illustration summarizing the arrangements seen in all cercariae represented a map of the basic nerve network for the species. Nerve commissures and cords were named according to the lettering system proposed by Richard (1971) and BayssadeDufour et al. (1993).

Silver nitrate impregnation - Approximately 100 cercariae were fixed in cold $3 \%$ silver nitrate solution, exposed to an artificial source of ultraviolet light, rinsed in cold distilled water, and mounted in Hoyer's medium on glass slides (Combes et al. 1976). Illustrations recorded the distribution of sensory receptors on the cercarial tegument of each specimen with the aid of a drawing tube. The chaetotaxic pattern was determined as described by Bogéa (1999).

Scanning electron microscopy - Fifty cercariae were fixed in a cold solution of $1.5 \%$ glutaraldehyde $/ 1.5 \%$ formaldehyde in $0.1 \mathrm{M}$ cacodylate buffer, postfixed in cold aqueous solution of $1 \%$ osmium tetroxide, dehydrated in a graded series of ethanol, and air-dried in hexamethyldisilazane (Ted Pella Inc., Redding, California), mounted on aluminum stubs, sputter-coated with approximately $100 \AA$ of gold/palladium, and examined using a Leo/Zeiss DSM982 Gemini field emission scanning electron microscope.

The external ultrastructure of each sensory receptor type was characterized based on characters previously established in the literature. The types were distinguished in at least 10 different specimens based on number of cilium-like structures, length of cilium-like structure, width of cilium-like structure, presence or absence of a tegumentary collar, length of tegumentary collar, and width of tegumentary collar. All measurements are in micrometers. Means were given followed by standard deviations and number of structures measured.

Due to their intrinsic properties, cercarial teguments are able to contract extensively during specimen preparation. Thus, the measurements of length of tegumentary collar and width of tegumentary collar were statistically compared among the different types of sensory receptors by the KruskalWallis One-Way Analysis of Variance by Ranks at a level of significance of 5\% and the Method of Multiple Comparisons between Treatments (Siegel \& Castellan 1988).

For identification purposes, each type of sensory receptor was designated with a letter code as follows. The first letter indicates the number of cilium-like structures and is either ' $U$ ' (for one structure) or ' $\mathrm{M}$ ' (for multiple structures). This is followed by a Roman numeral, which indicates the receptor type designation, and the letter 'A' corresponding to Allopodocotyle.

Transmission electron microscopy - Fifty cercariae were fixed in a cold solution of $1.5 \%$ glutaraldehyde $/ 1.5 \%$ formaldehyde $/ 1 \%$ acrolein in 0.1 $\mathrm{M}$ cacodylate buffer, rinsed in $0.1 \mathrm{M}$ cacodylate buffer, postfixed in $1 \%$ osmium tetroxide in $0.1 \mathrm{M}$ cacodylate buffer, washed in cold distilled water, dehydrated in a graded series of ethanol, and embedded in 100\% LRWhite resin (Polysciences Inc., Warrington, Pennsylvania). Gold serial sections from at least 10 specimens were cut using a LKB Ultratome III microtome with a diamond knife, mounted on uncoated copper grids, stained with $2 \%$ uranyl acetate and $2.5 \%$ lead citrate, and examined using a Phillips transmission electron microscope model 300. The internal ultrastructure of a subset of receptor types was characterized based on Lyons (1969). 


\section{RESULTS}

Nerve network - The basic arrangement of the nerve network is presented in Figs 1 and 2. The nervous system consisted of a large ramified cerebral ganglion $(\mathrm{G})$ located above the level of the pharynx and three pairs of lateral (L), dorsal (D), and ventral $(\mathrm{V})$ longitudinal nerve cords, which extended anteriorly and posteriorly from the cerebral ganglion. Four cephalic (CI, CII, CIII, and CIV), three anterior (AI, AII, and AIII), and three posterior (PI, PII, and PIII) transverse commissures were identified. Some of these commissures (AI, AII, and PI) were incomplete and did not surround the cercaria entirely. Fine connections branching from the ventral longitudinal nerve cords to the oral and ventral suckers were observed. A distinctive ring (S) was observed on the ventral sucker. A complex nerve network was observed on the dorsal surface of the tail $(\mathrm{U})$. On the ventral surface of the tail, two longitudinal nerve cords, one along each of the lateral margins of the tail, were observed. They branched into transverse commissures and fine ramifications.

Basic chaetotaxy - The basic chaetotaxy was examined in 96 of 100 cercariae of Allopodocotyle $\mathrm{sp}$. The cephalic, anterior, ventral sucker, posterior, and caudal nerve regions were schematically subdivided into 34 chaetotaxic sites. Approximately 172 sensory receptors were found on the cercarial tegument of Allopodocotyle sp.

External ultrastructure - Based on gross morphology seen with SEM, five types of sensory receptors were identified in 10 of 50 cercariae of Allopodocotyle sp. (Table I; Figs 3-7). The types were recognized as follows: receptors with a very high tegumentary collar and a short cilium-like structure (type UIA; Fig. 3), a moderately low tegumentary collar and a short cilium-like structure

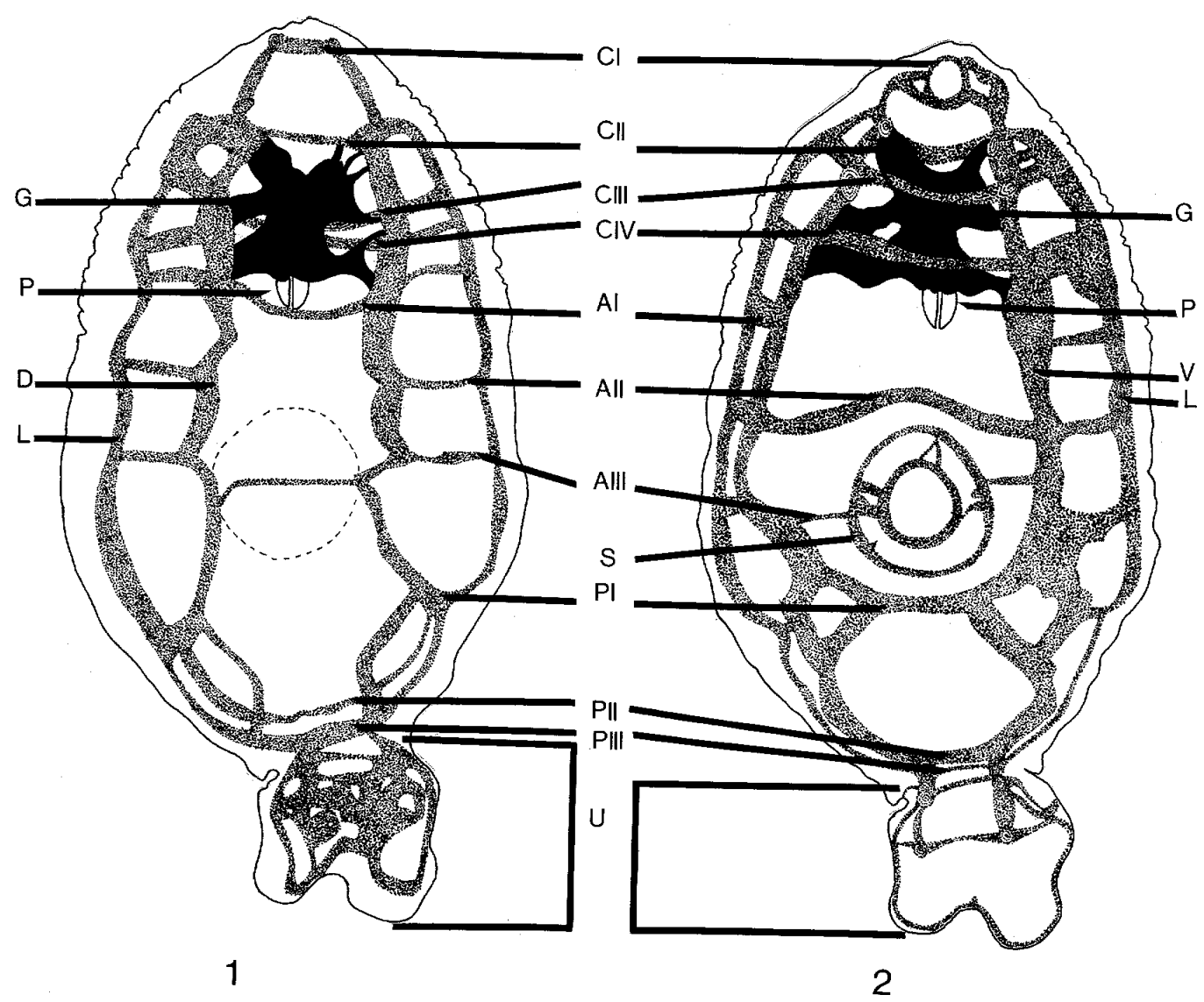

Arrangement of major transverse commissures and nerve cords in cercaria of Allopodocotyle sp. as seen with acetylthiocholine method for cholinesterase - Fig. 1: body and tail, dorsal view. Fig. 2: body and tail, ventral view. AI, AII, AIII: anterior transverse commissures; CI, CII, CIII, CIV: cephalic transverse commissures; D: dorsal nerve cord; G: cerebral ganglion; L: lateral nerve cord; P: pharynx; PI, PII, PIII: posterior transverse commissures; S: ventral sucker nerve region; U: caudal nerve cord; V: ventral nerve cord 


\section{TABLE I}

Types of sensory receptors in cercaria of Allopodocotyle sp. as seen with scanning electron microscopy.

Measurements are in micrometers and include mean followed by standard deviation and number of receptors measured

\begin{tabular}{lccccccccc}
\hline Type & $\mathrm{CN}$ & $\mathrm{CL}$ & $\mathrm{n}$ & $\mathrm{CW}$ & $\mathrm{n}$ & $\mathrm{TCL}$ & $\mathrm{n}$ & TCW & $\mathrm{n}$ \\
\hline UIA & 1 & $1.30 \pm 0.43$ & 06 & $0.30 \pm 0.16$ & 06 & $0.96 \pm 0.22$ & 06 & $0.90 \pm 0.21$ & 06 \\
UIIA & 1 & $1.00 \pm 0.40$ & 12 & $0.22 \pm 0.06$ & 12 & $0.30 \pm 0.15$ & 18 & $0.80 \pm 0.33$ & 18 \\
UIIIA & 1 & $1.16 \pm 0.27$ & 04 & $0.51 \pm 0.15$ & 04 & $-a$ & - & - & - \\
MIA & 4 & $2.80 \pm 0.57$ & 07 & $0.16 \pm 0.01$ & 07 & $0.18 \pm 0.06$ & 07 & $0.85 \pm 0.17$ & 07 \\
MIIA & 7 & $1.90 \pm 0.51$ & 06 & $0.14 \pm 0.06$ & 07 & $1.20 \pm 0.55$ & 08 & $0.67 \pm 0.21$ & 09 \\
\hline
\end{tabular}

$a$ : with no tegumentary collar; $\mathrm{CN}$ : number of cilium-like structures; n: number of receptors measured; CL: length of cilium-like structure; CW: width of cilium-like structure; TCL: length of tegumentary collar; TCW: width of tegumentary collar; UIA: receptor with a very high tegumentary collar and a short cilium-like structure; UIIA: receptor with a moderately low tegumentary collar and a short cilium-like structure; UIIIA: receptor with no tegumentary collar and a short, wide, and stiff structure; MIA: receptor with a low tegumentary collar and four moderately long and long cilium-like structures; MIIA: receptor with a very high tegumentary collar and seven moderately long and long cilium-like structures

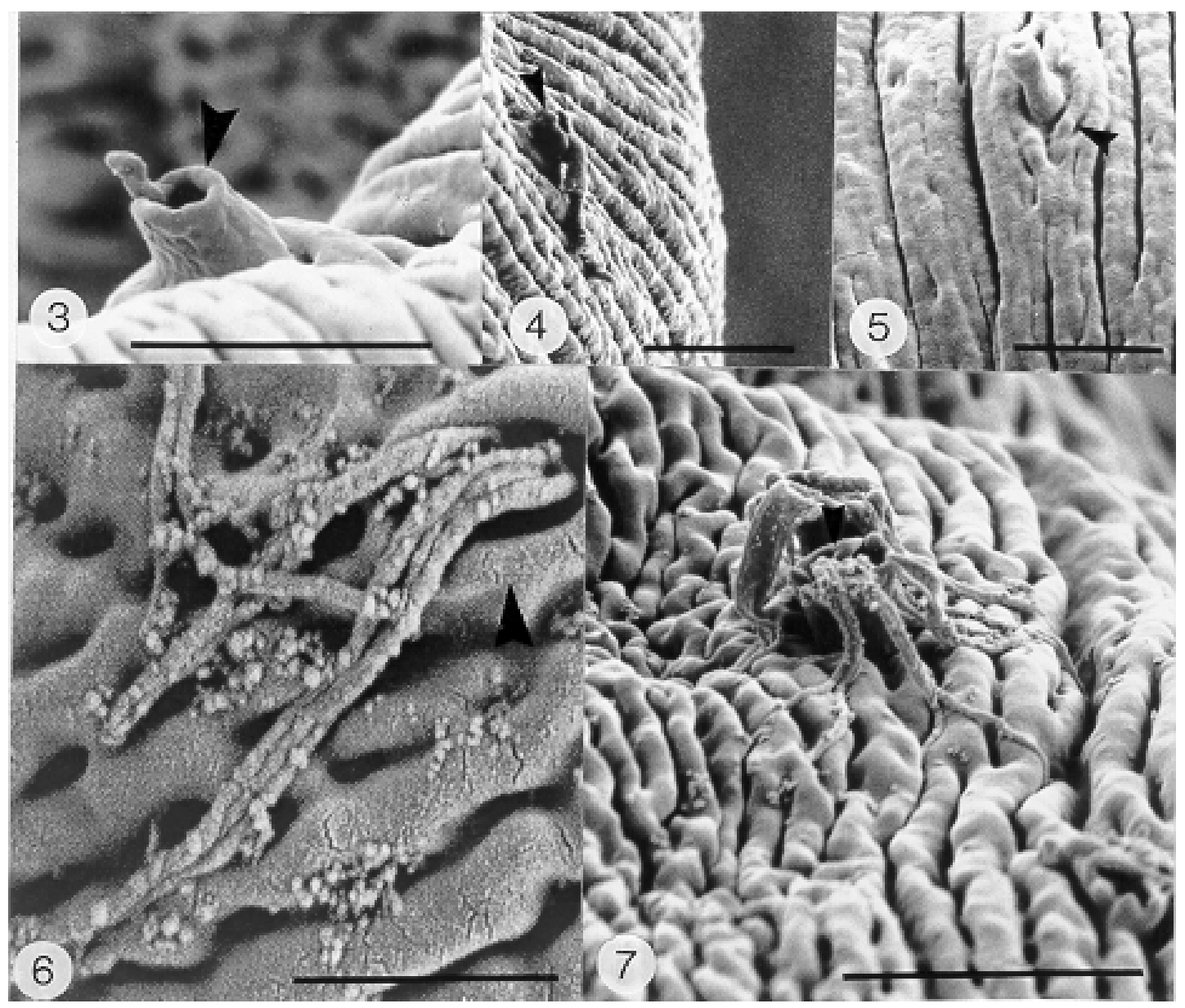

Scanning electron micrographs of types of sensory receptors in cercaria of Allopodocotyle sp. Fig. 3: type UIA. Fig. 4: type UIIA. Fig. 5: type UIIIA. Fig. 6: type MIA. Fig. 7: type MIIA. Codes (UIA-MIIA) refer to sensory receptor types shown in Table I. 
(type UIIA; Fig. 4), no tegumentary collar and a short, wide, and stiff structure with a pore on its tip (type UIIIA; Fig. 5), a low tegumentary collar and four moderately long and long cilium-like structures (type MIA; Fig. 6), and a very high tegumentary collar and seven moderately long and long cilium-like structures (type MIIA; Fig. 7).

The results of the statistical analyses validated the morphological differences in length of tegumentary collar among the types of sensory receptors in the cercaria of Allopodocotyle sp. Thus, these analyses confirmed that types UIA and MIIA exhibited significantly higher tegumentary collars than types UIIA and MIA (Table II).

Internal ultrastructure - The internal ultrastructure of type UIIA was investigated (Fig. 8). The short cilium-like structure projecting from a tegumentary collar of approximately $0.4 \mu \mathrm{m}$ long was found to lack a sheath. A basal body was observed. Type UIIA exhibited thickened nerve collars.

A type of sensory receptor not observed with SEM was described when this cercaria was studied with TEM (Fig. 8). This receptor was located on the cephalic region. It had a sensory bulb attached to the tegument with septate extracellular junctional complexes, two pairs of thickened nerve

\section{TABLE II}

Morphological differences among types of sensory receptors in cercaria of Allopodocotyle sp. as indicated by Kruskal-Wallis One-Way Analysis of Variance and the Method of Multiple Comparisons between treatments. Table shows the critical z-values estimated for all individual pairs of comparisons

\begin{tabular}{lll}
\hline Pairs of comparisons & $\mathrm{TCL}^{a}$ & $\mathrm{TCW}^{b}$ \\
\hline Types UIA X UIIA & $13.14^{c}$ & 13.49 \\
Types UIA X MIA & $16.28^{c}$ & 16.69 \\
Types UIA X MIIA & 15.69 & 15.61 \\
Types UIIA X MIA & 14.40 & 14.74 \\
Types UIIA X MIIA & $13.73^{c}$ & 13.49 \\
Types MIA X MIIA & $16.75^{c}$ & 16.69 \\
\hline
\end{tabular}

$a: \mathrm{KW}=32.16 ; b: \mathrm{KW}=2.70 ; c$ : significant at $\mathrm{p}<0.05$; TCL: length of tegumentary collar; TCW: width of tegumentary collar; UIA: receptor with a very high tegumentary collar and a short cilium-like structure; UIIA: receptor with a moderately low tegumentary collar and a short cilium-like structure; MIA: receptor with a low tegumentary collar and four moderately long and long cilium-like structures; MIIA: receptor with a very high tegumentary collar and seven moderately long and long cilium-like structures

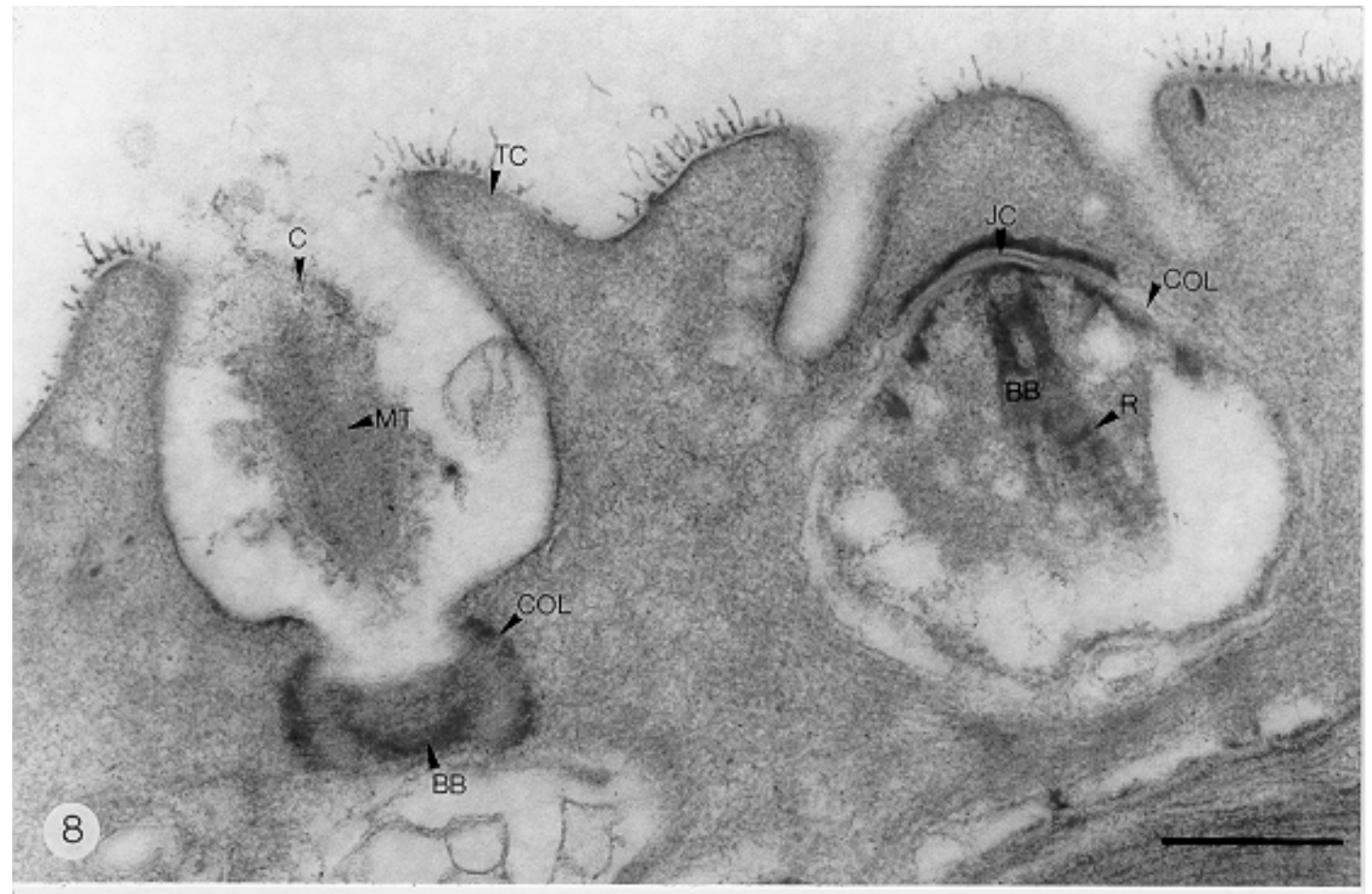

Transmission electron micrograph of sensory receptors in cercaria of Allopodocotyle sp. Fig. 8: type UIIA. A subtegumentary sensory receptor is shown on the right. Bar $=0.5 \mu \mathrm{m}$. BB: basal body; C: cilium-like structure; COL: thickening of nerve collar; JC: extracellular junctional complex; MT: microtubules; TC: tegumentary collar; R: ciliary rootlet. Code (UIIA) refers to sensory receptor type shown in Table I. 
collars, a closed basal body, and a distinctive bifurcated ciliary rootlet. No cilium-like structure was observed in this type of receptor.

In addition, a complex structure also not observed with SEM was detected with TEM on the cercaria of Allopodocotyle sp. (Fig. 9). This structure was located on the ventral surface of the cephalic region. It was approximately $2.6 \mu \mathrm{m}$ long and had many microtubules enclosed in a single envelope. The envelope was covered by a thick tegumentary sheath that exhibited electron-dense extensions throughout its external surface.

Chaetotaxic and site-specific patterns - Following superimposition of the chaetotaxic map generated from silver nitrate impregnation on the respective nerve network map obtained with the acetylthiocholine method for cholinesterase, groups of sensory receptors were associated with the cephalic, anterior, ventral sucker, posterior, and caudal nerve regions. In general, receptors were found to be concentrated in the cephalic region (78 of 172, or 45.4\%) (Figs 10-13).

SEM confirmed the chaetotaxic pattern detected with silver nitrate impregnation in the cercaria of Allopodocotyle sp. This pattern is illustrated in Figs $10-13$ and the chaetotaxic nomenclature is summarized as follows:

Cephalic region (number of receptors on each side of the cercaria): $\mathrm{CI}=1 \mathrm{CI}_{2}, 5 \mathrm{CI}_{4}, 1 \mathrm{CI}_{5}$; $\mathrm{CII}=$ $1 \mathrm{CII}_{2}, 2 \mathrm{CII}_{4}, 1 \mathrm{CII}_{5} ; \mathrm{CIII}=3 \mathrm{CIII}_{2}, 2 \mathrm{CIII}_{4}, 16-18$ $\mathrm{CIII}_{5} ; \mathrm{CIV}=2 \mathrm{CIV}_{2}, 1 \mathrm{CIV}_{4}, 3 \mathrm{CIV}_{5}$.

Anterior region (number of receptors/side of the cercaria): AI= 2 AIV, 1-2 AIL, 2 AID; AII $=2$ AIIV, 1-2 AIIL, 3 AIID; AIII= 3 AIIIV, 1 AIIIL, 3 AIIID.

Posterior region (number of receptors/side of the cercaria): PI= 2 PIV, 1 PIL, 1 PID; PII= 1 PIIL, 3 PIID; PIII= 3 PIIIV, 1 PIIIL, 1 PIIID.

Ventral sucker region (total number of receptors): $\mathrm{S}=1-2 \mathrm{SI}, 6 \mathrm{SII}, 6 \mathrm{SIII}$.

Caudal region: $\mathrm{U}=6 \mathrm{UD}, 4 \mathrm{U}$ DL.

The distribution of the five types of sensory receptors for the cephalic, anterior, acetabular, posterior, and caudal regions is summarized in Figs 10-13. Sensory receptors with a very high tegumentary collar and a short cilium-like structure (type UIA) were mainly observed ventrally around the oral opening (Fig. 12). Type UIIA, with a moderately low tegumentary collar and a short cilium-like structure, was found widespread throughout the cercarial body (Fig. 11). Three pairs of receptor type UIIIA, with no tegumentary collar and a short, thick, and stiff structure with a pore on its tip, were observed dorso-laterally each on the cephalic, anterior, and posterior regions of the cercaria (Figs 11-12). Sensory receptors with mul- tiple cilium-like structures and a low (type MIA) or a very high tegumentary collar (type MIIA) were mostly found on the ventral surface of the cephalic region (Fig. 12).

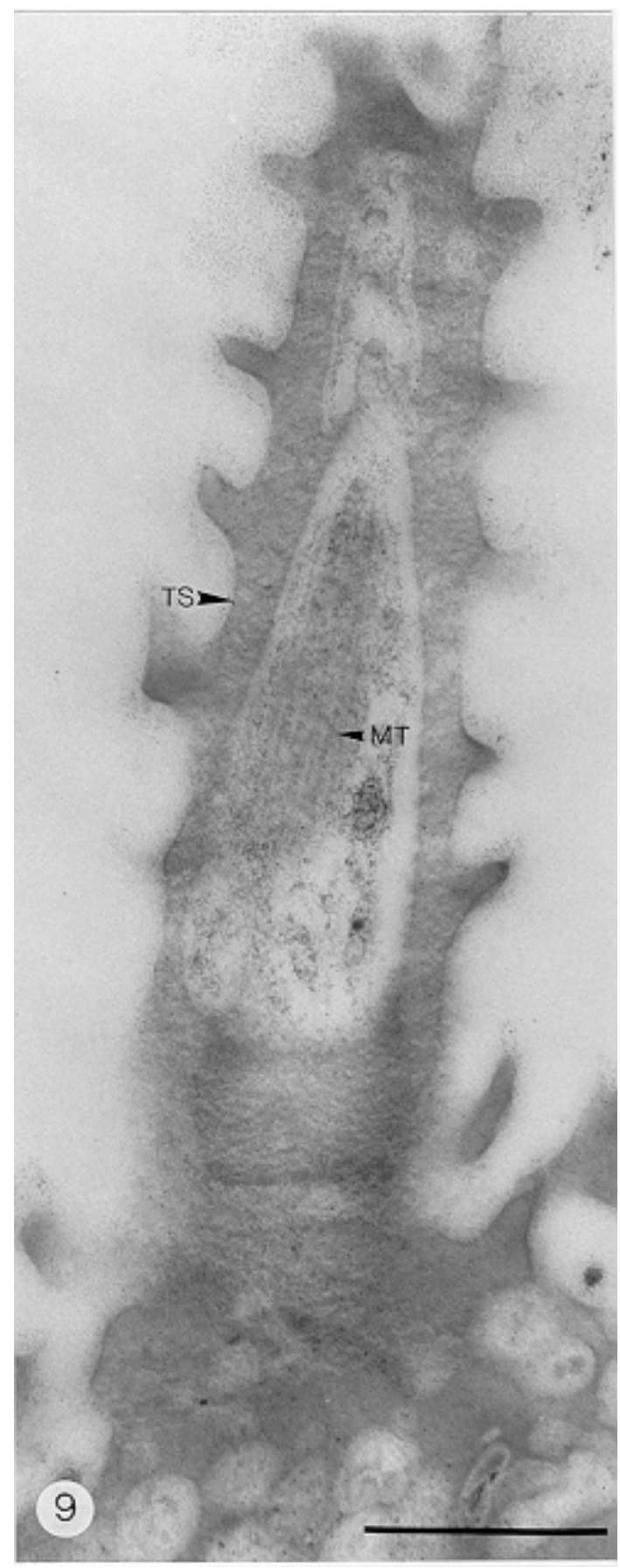

Transmission electron micrograph of a possible sheathed sensory receptor in cercaria of Allopodocotyle sp. Fig. 9: sheathed structure. Bar $=0.5 \mu \mathrm{m}$. MT: microtubules; TS: tegumentary sheath 


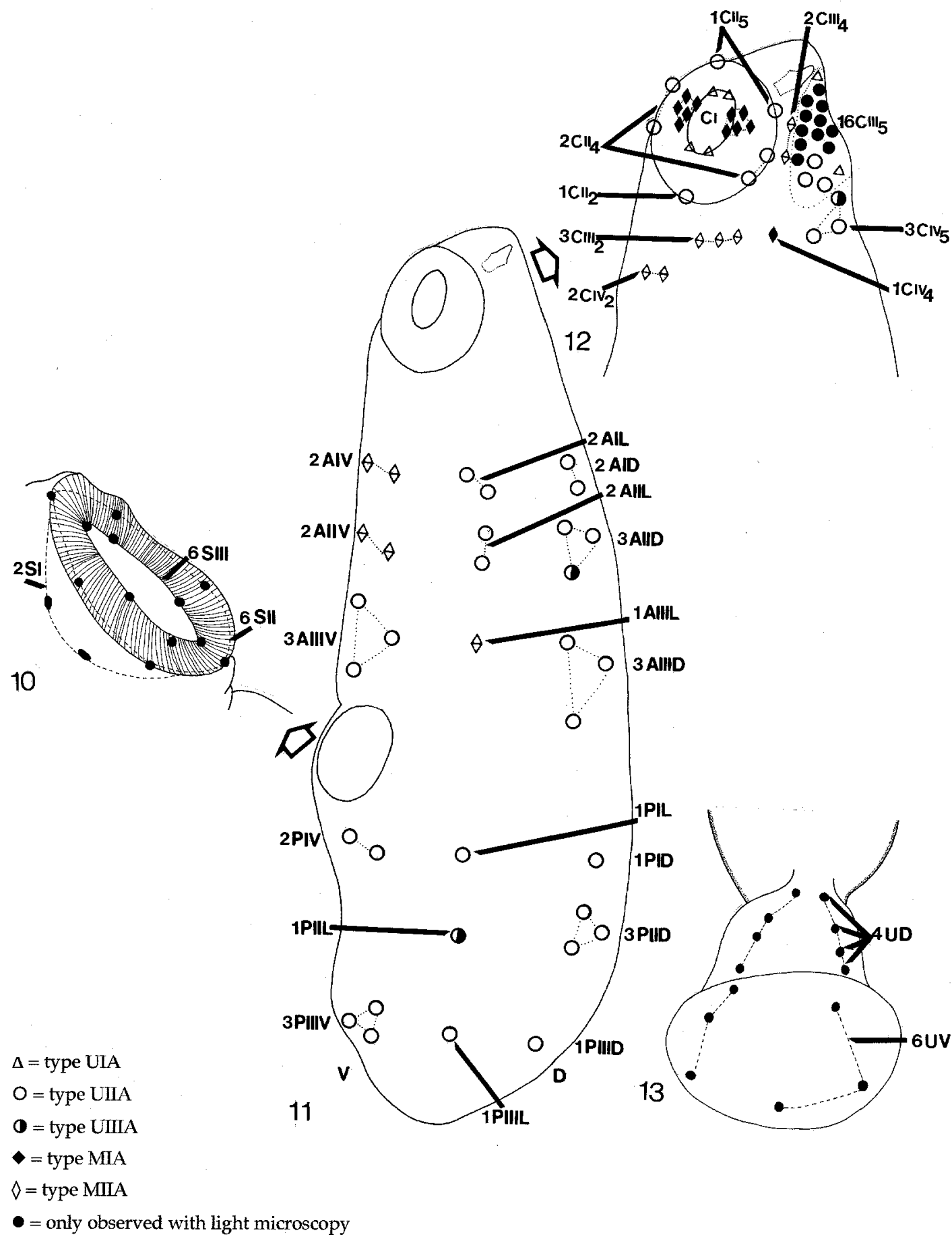

Sensory receptors in cercaria of Allopodocotyle sp. identified using acetylthiocholine method for cholinesterase, silver nitrate impregnation, and scanning electron microscopy. Identification of sensory receptors associated with transverse commissures of each nerve region is shown. C, A, S, P, and U refer to sensory receptors located in cephalic, anterior, ventral sucker, posterior, and caudal nerve regions, respectively. Fig. 10: sensory receptors associated with ventral sucker (S) region, ventral view. Fig. 11: sensory receptors associated with anterior (AI, AII, and AIII) and posterior (PI, PII, and PIII) transverse commissures, lateral view. Fig. 12: sensory receptors associated with cephalic transverse commissures CI, CII, CIII, and CIV, anteroventral view. Fig. 13: sensory receptors associated with caudal (U) nerve cords, dorsal and ventral views. D: dorsal surface; v: ventral surface. Symbols refer to sensory receptor types shown in Table I. Black dots indicate sensory receptors only observed with light microscopy. 


\section{DISCUSSION}

SEM observations suggest that there are five basic types of sensory receptors in the cercaria of Allopodocotyle sp. (Table I; Figs 3-7). These types vary in their lack of a tegumentary collar, number of cilium-like structures, as well as short, moderately long, or long cilium-like structures, and a low, a moderately low, or a very high tegumentary collar.

Some of the five sensory receptor types detected in the cercaria of Allopodocotyle sp. are similar to types previously described in other opecoelid cercariae. For example, the short ciliated papillae detected in A. lepomis by Lo et al. (1975) and type 1 found in Podocotyle reflexa by Køie (1981) correspond well to type UIIA of Allopodocotyle sp. These receptors exhibit a short cilium of approximately $1 \mu \mathrm{m}$ long surrounded by a moderately low tegumentary collar. It is possible that Køie's type 3 , described as a pit with a tuft of up to 12 cilia of 2-8 $\mu \mathrm{m}$ long, corresponds to type MIA of Allopodocotyle sp. However, because Køie (1981) provided a written description of this type, this assumption remains to be confirmed. Further investigations are necessary to determine whether the remaining four types of receptors found in the cercaria of Allopodocotyle sp. also occur in other species of opecoelid cercariae.

Some cercarial sensory receptor types observed in Allopodocotyle sp. resemble those described in cercariae of other families. In the family Coitocaecidae, the cotylomicrocercous cercaria of Nicolla gallica (Dollfus, 1941) Dollfus, 1958 was found to exhibit long, uniciliated sensory receptors with a low tegumentary collar (Pariselle \& Matricon-Gondran 1985). Multiple villi were seen extending from the tegumentary collar and surrounding this cilium. According to the authors, these villi probably function as real "stereocilia". In the present study, ultrastructural investigations revealed two types of receptors with multiple cilium-like structures (types MIA and MIIA), both of which possessed a tegumentary collar, but no villi. This may indicate that the sensory receptors found in Allopodocotyle sp. and those seen in $N$. gallica function differently.

Several types of sensory receptors seen in the cercaria of Allopodocotyle sp. were site-specific (Figs 10-13). For example, type UIA (with a very high tegumentary collar and a short cilium-like structure) occurred mainly on the cephalic region. Type UIIA (with a moderately low tegumentary collar and a short cilium-like structure) was found widespread throughout the cercarial body. Type UIIIA, with no tegumentary collar and a short, wide, and stiff structure with a pore on its tip, oc- curred in specific areas: three pairs were found, each one on the cephalic, anterior, and posterior regions of the cercarial body. Sensory receptors with multiple cilium-like structures and a low (type MIA), or a very high (type MIIA) tegumentary collar were found only on the ventral surface of the cephalic region. These results are consistent with that of Køie (1981), who observed site-specificity in some types of sensory receptors found in the cercaria of $P$. reflexa.

The internal ultrastructure of type UIIA was studied in the cercaria of Allopodocotyle sp. It had a short, unsheathed cilium-like structure, a basal body, and thickened nerve collars (Fig. 8). Short uniciliated receptors consistent with type UIIA of Allopodocotyle sp. examined here with TEM have been investigated previously in other cercariae. For example, Gibson (1974) examined these receptors in cercariae of $P$. staffordi and found that they exhibit an unsheathed cilium emerging from the sensory bulb, a closed basal body, thickened nerve collars, and many electron-dense vesicles of approximately $90 \mathrm{~nm}$. This morphology resembles that of the receptors of Allopodocotyle sp., suggesting that the internal ultrastructure of short uniciliated receptors may be similar among different species of opecoelid cercariae.

Subtegumentary sensory receptors have been described in platyhelminths, such as amphilinids and aspidogastreans (Rohde \& Garlick 1985, Rohde et al. 1986, Rohde 1990). In general, these receptors are characterized by their position in the tegument, lack of cilia, possession of a distinctive ciliary rootlet, as well as many small electron-lucent vesicles dispersed throughout the sensory bulb. They may act as proprioceptors and are probably sensitive to changes in pressure on the body surface and/or within the body (Rohde \& Garlick 1985). TEM suggested that the subtegumentary sensory receptor of Allopodocotyle sp. examined here shares several features with these receptors, such as no cilium emerging through the tegument, a sensory bulb attached to the tegument by septate junctional complexes, thickened nerve collars, a closed basal body, and a bifurcated ciliary rootlet (Fig. 8). It may therefore function as a proprioceptor.

Comparative studies on sensory receptor ultrastructure are useful in further elucidating the sensory modalities with which the receptors are associated. The internal ultrastructure of type UIIA revealed an unsheathed cilium-like structure (Thurm 1968) as well as a basal body. This suggests that the transduction mechanism may be similar to that of mechanoreceptors of other invertebrates (Thurm 1968, Lyons 1969). Other ultrastructural characters provide useful information. 
For example, the very high tegumentary collar of type UIA would seem to restrict cilium movement more than the moderately low tegumentary collar of type UIIA. It seems that, given the differences in tegumentary collar height, the former might be subjected to higher mechanical stimuli than the latter. On the other hand, the low tegumentary collar of type MIA might allow moderately long and long cilia to respond more promptly to low mechanical stimuli such as those elicited by water currents.

The mechanoreception of sensory receptors in the cercaria of Allopodocotyle sp. should be considered in conjunction with the transmission of this parasite to the second intermediate host. This cotylomicrocercous cercaria crawls with the aid of both suckers to find a host, eventually attaching to the substratum with its glandular tail and then wagging the anterior end of its body back and forth until a suitable host is contacted (Hunninen \& Cable 1943, Lo et al. 1975, Køie 1981). Due to its biology, sensory receptors with long cilia might be expected to be concentrated around the anterior end of the body and not on the dorsal surface, as seen in free-swimming cercariae (Bogéa 1998, Bogéa \& Caira 2001). In fact, types MIA and MIIA, with their moderately long and long cilium-like structures, were found around the oral opening at the anterior end of the body, suggesting that these receptors may respond to water currents. The cotylomicrocercous cercariae of opecoelids $A$. lepomis and $P$. reflexa, which exhibit similar biologies, also have long uniciliated sensory receptors around the oral opening (Lo et al. 1975, Køie 1981).

A large sheathed structure was also detected in the cercaria of Allopodocotyle sp. It was found on the ventral surface of the cephalic region and is characterized by the possession of microtubules surrounded by a long, thick, and stiff ornamented tegumentary sheath (Fig. 9). Its internal ultrastructure resembles that of the sensory bristles described in insects and arachnids. In these bristles, the dendritic processes of the sensory receptor are enclosed in a cuticular sheath. Such processes are connected to the sheath by means of a ciliary structure. The sensory bristles serve a double function of mechano- and chemoreception (Bareth \& Juberthie-Jupeau 1977). Further investigations on the internal ultrastructure of this sheathed structure are necessary to verify its sensory nature.

The present work extends the investigation of chaetotaxic patterns in the family Opecoelidae to the genus Allopodocotyle. In the past, the chaetotaxic arrangements in cercariae of opecoelids Sphaerostoma bramae, Cercaria 10, Cercaria 11, Cercaria 12 have been described by Richard
(1971). Lambert (1972) described the cercarial chaetotaxy of opecoelids Sphaerostoma maius and Cercaria micrura, and Bayssade-Dufour and Maillard (1974) examined the chaetotaxy in Cainocreadium labracis. Although the chaetotaxic maps were different for each species, the arrangement of cephalic circle CI (1 CIV , 4-5 CIL, 1 CID) was similar among all species. Thus, BayssadeDufour (1979) identified the chaetotaxic arrangement of this circle as a diagnostic character for the family Opecoelidae. Based on the chaetotaxic nomenclature of Bayssade-Dufour et al. (1993), the cercaria of Allopodocotyle sp. was found to share a similar arrangement of cephalic circle $\mathrm{CI}\left(1 \mathrm{CI}_{2}\right.$, $5 \mathrm{CI}_{4}, 1 \mathrm{CI}_{5}$ ) with these species.

The arrangement of the cholinergic nerve network is shown here for the cercaria of Allopodocotyle sp. for the first time. Cholinergic components were demonstrated in the cerebral ganglion, nerve cords, and transverse commissures. Fine connections branching from the ventral nerve cords to the ventral sucker suggest that the lateral nerve cords innervate the sensory receptors found in this region. Five nerve regions were clearly identified. Similar arrangements had been previously determined by Nezlin et al. (1992) for the cholinergic nerve networks of the cercaria of Podocotyle atomon (Rudolphi, 1802) Odhner, 1905, the only other opecoelid species in which nerve networks had been examined. In this species, however, three cephalic transverse commissures and two caudal longitudinal cords were observed. The present results indicate that the basic arrangement of the cholinergic nerve network may vary among cercariae of different species of opecoelids.

Recent investigations have demonstrated that cercarial nervous systems are far more complex than originally presumed (Halton et al. 1997). Peptidergic and cholinergic elements seem to cooccur in the neurons, whereas serotonergic components are located in different sets of neurons. The demonstration of cholinergic components in the cercarial nervous system of Allopodocotyle sp. should encourage future investigations on its peptidergic and serotonergic components.

\section{ACKNOWLEDGEMENTS}

To Kenneth Tiekotter for his invaluable technical assistance as well as for providing us with the infected snails. Dr Eileen Jokinen kindly identified the snails. Desley Scott provided us with the protocol for preparing whole mounts of cercariae. Jim Romanow and Drs Marie Cantino, Charles Henry, and Lamia Khairallah provided technical assistance and advice throughout the course of this study. To Dr Carl Schaefer for critically reviewing an earlier version of this manuscript and to two anonymous reviewers for their comments. 


\section{REFERENCES}

Bareth C, Juberthie-Jupeau L 1977. Ultrastructure des soies sensorielles des palpes labiaux de Campodea sensillifera (Conde et Mathieu) (Insecta: Diplura). Int J Insect Morphol and Embryol 6: 191-200.

Bayssade-Dufour Ch 1979. L'appareil sénsoriel des cercaries et la systématique des trématodes digenétiques. Mém Mus Natn Hist Nat (Paris) Série A, 113: 1-81.

Bayssade-Dufour Ch, Maillard C 1974. Chétotaxie de quatre d'Allocreadioidea. Ann Parasitol Hum Comp (Paris) 49: 521- 554.

Bayssade-Dufour Ch, Hugot J-P, Albaret J-L 1993. Analyse phénétique des Microphalloidea (Trematoda) d'après la chétotaxie des cercaires. Syst Parasitol 25: 1-24.

Bogéa T 1998. Distribution and morphology of sensory papillae in the cercaria of Allassogonoporus marginalis (Digenea: Lecithodendriidae). Parasitol Int 47: 120.

Bogéa T 1999. Ultrastructure and Chaetotaxy of Cercarial Sensory Receptors: a Comparative Analysis of Four Species of Digenea (Platyhelminthes), $\mathrm{PhD}$ Thesis, University of Connecticut, $253 \mathrm{pp}$.

Bogéa T, Caira JN 2001. Ultrastructure and chaetotaxy of sensory receptors in the cercariae of a species of Crepidostomum Braun, 1900 and Bunodera Railliet, 1896 (Digenea: Allocreadiidae). J Parasitol 87: in press.

Bray RA 1987. Some helminth parasites of marine fishes of South Africa: family Opecoelidae (Digenea). $J$ Nat Hist 21: 1049-1075.

Combes C, Bayssade-Dufour Ch, Cassone J 1976. Sur l'impregnation et le montage des cercaires pour l'étude chétotaxique. Ann Parasitol Hum Comp (Paris) 51: 399-400.

Dobrovolny CG 1939. The life history of Plagioporus lepomis, a new trematode from fishes. J Parasitol 25: 461-471.

Gibson DI 1974. Aspects of the ultrastructure of the daughter sporocyst and cercaria of Podocotyle staffordi Miller, 1941 (Digenea: Opecoelidae). Norw J Zool 22: 237-252.

Gibson DI, Bray RA 1982. A study and reorganization of Plagioporus Stafford, 1904 (Digenea: Opecoelidae) and related genera, with special reference to forms from European Atlantic waters. $J$ Nat Hist 16: 529-559.

Halton DW, Maule AG, Shaw C 1997. Trematode neurobiology. In B Fried, TK Graczyk (eds), Advances in Trematode Biology, CRC Press, USA, p. 345-382.

Hunninen AV, Cable RM 1943. The life history of Podocotyle atomon (Rudolphi) (Trematoda:
Opecoelidae). Trans Am Microsc Soc 62: 57-68.

Køie M 1981. On the morphology and life-history of Podocotyle reflexa (Creplin, 1825) Odhner, 1905, and a comparison of its developmental stages with those of $P$. atomon (Rudolphi, 1802) Odhner, 1905 (Trematoda, Opecoelidae). Ophelia 20: 17-43.

Lambert M 1972. Recherches sur la Biologie des Trématodes dont Bythinia tentaculata (Mollusque Prosobranche) Représentente le Premier Hôte Intermédiaire dans la Région de Montpellier, $\mathrm{PhD}$ Thesis, Université de Montpellier, 201 pp.

Lo SJ, Hall JE, Allonder PA, Kleiner RA 1975. Scanning electron microscopy of an opecoelid cercaria and its encystment and encapsulation in an insect host. J Parasitol 61: 413-417.

Lyons KM 1969. Sense organs of monogean skin parasites ending in a typical cilium. Parasitology 59: 611-623.

McIntosh A 1939. A new allocreadiid trematode, Podocotyle shawi, n. sp., from the silver salmon. $J$ Wash Acad Sci 29: 379-381.

Nezlin LP, Rybakov AV, Kontrimavichyute DV 1992. Histochemical study of the nerve system of Podocotyle atomon cercariae (Trematoda: Opecoelidae). Parazitologia 26: 115-121.

Pariselle A, Matricon-Gondran M 1985. A new type of ciliated sensory receptor in the cercariae of Nicolla gallica (Trematoda). Z Parasitenkd 71: 353-364.

Pritchard MH 1966. A revision of the genus Podocotyle (Trematoda: Opecoelidae). Zool Jb Syst 93: 158172.

Richard J 1971. La chétotaxie des cercaires: valeur systématique et phylétique. Mém Mus Natn Hist Nat (Paris), Série A, 67: 1-179.

Rohde K 1990. Ultrastructure of the sense receptors of adult Multicotyle purvisi (Trematoda, Aspidogastrea). Zool Scr 19: 233-241.

Rohde K, Garlick, PR 1985. Subsurface sense receptors in the larva of Austramphilina longata Johnston, 1931 (Amphilinidea). Zoomorphology 105: 34-38.

Rohde K, Watson N, Garlick PR 1986. Ultrastructure of three types of sense receptors of larval Austramphilina longata (Amphilinidea). Int $J$ Parasitol 16: 245-251.

Shaw JN 1947. Some parasites of Oregon wild life. Oregon Stat Col Agric Exp Stat Tech Bull 11: 1-16.

Siegel S, Castellan Jr NJ 1988. Nonparametric Statistics for the Behavioral Sciences, McGraw-Hill, New York, $399 \mathrm{pp}$.

Thompson S W 1966. Selected Histochemical and Histopathological Methods, Charles C Thomas, Springfield, $1639 \mathrm{pp}$.

Thurm U 1968. Steps in the transducer process of mechanoreceptors. Symp Zool Soc London 23: 199-216. 